\title{
Age Does not Matter, Biology of Both Cancer and Patient Does
}

\author{
Matti S. Aapro \\ Multidisciplinary Institute of Oncology, Clinique de Genolier, Switzerland
}

At the recent San Antonio Breast Cancer Symposium, Professor Hyman Muss received the Brinker Award for Scientific Distinction in Clinical Research for his achievements in the field of breast cancer, in particular in senior patients. Among the many contributions of Hyman Muss to the improvement of care of elderly breast cancer patients, one work is of prime importance [1]: In the late 1990s he was able to convince his Cancer and Leukemia Group B (CALGB) colleagues to start a study on adjuvant chemotherapy in elderly breast cancer patients when there was still considerable skepticism about the value of adjuvant chemotherapy for such patients. This negative view was in part related to wrong interpretation of existing data and to the paucity of results in the older population. The CALGB 49907 trial started in 2001 and has clearly shown that polychemotherapy is superior to single-agent therapy, as administered in the study. In retrospective analyses the study also shows that this benefit tends to be limited to the hormone receptor-negative population. But lately we have been told that polychemotherapy is of equal benefit (same proportional advantage) in endocrine responsive and nonresponsive populations, according to the Early Breast Cancer Trialists' Collaborative Group (EBCTCG) [2], maybe because of longer use of anthracyclines and/or taxanes, which were not employed in the CALGB study. It would be sad to again go in the wrong direction because of a statistical value which does not take into account the fact that there are two categories of estrogen receptor-positive patients: those with low risk of recurrence (patients with so-called luminal A cancers), who will have no or very limited benefit from chemotherapy, and the others. Thus, as always, one should not forget biology.

The many questions related to adjuvant chemotherapy in elderly breast cancer patients are discussed in this issue of Breast CARE, with emphasis on the biology of the patient - in other words on the probability of tolerance and benefit of the treatment in terms of expected survival [3]. But if chemotherapy is still debated in the elderly, what about surgery?
Why is it that a relatively simple procedure is not routinely offered to the older patients? Hip surgery is not disputed, but breast surgery is. We know how to evaluate the surgical risk of elderly patients, with simple yet powerful tools that can determine the need for more or less intensive post-surgery, post-anesthesia surveillance in such patients [4]. A paper reported in this issue looks at the choices available and - very importantly - discusses the little we know about the real preferences of the older segment of our patient population [5]. Some patients may well decide for mastectomy, because it will often spare them several weeks of radiation therapy, which remains a standard even in older patients. But this choice does not take into account the possibilities of intraoperative radiation therapy, now offered in many centers, and accepted at the St. Gallen consensus conference as an option in patients above the age of 70 [6]. Until recently the boost on the tumor bed was also presented simply as an option in older patients, while, with longer follow-up, it is now clear that the risk of local relapse is high, as discussed in this issue [7]. However, one should take into account the patient's life expectancy when offering treatments which may not be of value as other causes of mortality can be predominant.

All 3 papers related to breast cancer in the elderly person come from colleagues who were part of the International Society of Geriatric Oncology (SIOG) and European Society of Breast Cancer Specialists (EUSOMA) panel which provided recommendations for the treatment of elderly patients with breast cancer [8]. That expert review provides updated information on many areas which are not covered by these papers. An area of particular importance may be the early detection of breast cancer, as older patients tend to present with more advanced tumors. The SIOG EUSOMA group indicates that the U.S. Preventive Services Task Force concluded that there is insufficient data for women $\geq 70$ years on the effect of mammographic screening on breast cancer mortality. However, modeling studies suggest that mortality reduction can be achieved on a cost-effective scale until the

\section{KARGER}

Fax +497614520714

Information@Karger.de

www.karger.com (c) 2012 S. Karger GmbH, Freiburg

1661-3791/12/0076-0434\$38.00/0

Accessible online at:

www.karger.com/brc
Matti S. Aapro, MD

Multidisciplinary Institute of Oncology

Clinique de Genolier

3 route du Muids, 1272 Genolier, Switzerland

maapro@genolier.net 
age of 74 and actually population screening up to 74 years is recommended in several European countries. Beyond that age the decision to look for occult breast cancer should be made by the individual patient and her clinician, based on risks and benefits of screening, patient preference, and life expectancy. And one should not forget that $15-18 \%$ of older patients may have highly aggressive 'triple-negative' tumors
(TNBC), even if some emerging studies suggest that older patients with TNBC may have a better outcome when compared with their younger counterparts. The reasons for these differences in prognosis have yet to be fully elucidated, but may be due to age-related biological variations, as suggested by observed differences in the distribution of histological subtypes of TNBC, or perhaps other unknown (biological) factors [9].

\section{References}

1 Muss HB, Berry DA, Cirrincione CT, et al.: Adjuvant chemotherapy in older women with earlystage breast cancer. N Engl J Med 2009;360:20552065.

2 Early Breast Cancer Trialists' Collaborative Group (EBCTCG): Comparisons between different polychemotherapy regimens for early breast cancer: meta-analyses of long-term outcome among 100,000 women in 123 randomised trials. Lancet 2012;379:432-444.

3 Loibl S, Reinisch M: Present status of adjuvant chemotherapy for elderly breast cancer patients. Breast Care 2012;7: DOI: 10.1159/000345867.
4 PACE participants: Shall we operate? Preoperative assessment in elderly cancer patients (PACE) can help - a SIOG surgical task force prospective study Crit Rev Oncol Hematol 2008; 65:156-163.

5 Swaminathan V, Markos K Spiliopoulos MK, Audisio RA: Choices in surgery for older women with breast cancer. Breast Care 2012;7: DOI: $10.1159 / 000345402$

6 Goldhirsch A, Wood WC, Coates AS, et al.: Strategies for subtypes - dealing with the diversity of breast cancer: highlights of the St. Gallen International Expert Consensus on the Primary Therapy of Early Breast Cancer 2011. Ann Oncol 2011;22:1736-1747.
7 Kunkler I: Radiotherapy issues in elderly breast cancer patients. Breast Care 2012;7: DOI: 10.1159/000345870.

8 Biganzoli L, Wildiers H, Oakman C, Marotti L, Loibl S, Kunkler I, Reed M, Ciatto S, Voogd AC, Brain E, Cutuli B, Terret C, Gosney M, Aapro M, Audisio R: Management of elderly patients with breast cancer: updated recommendations of the International Society of Geriatric Oncology (SIOG) and European Society of Breast Cancer Specialists (EUSOMA). Lancet Oncol 2012;13:e148-160.

9 Aapro M, Wildiers H: Triple-negative breast cancer in the older population. Ann Oncol 2012; 23(suppl 6):vi52-55. 